\title{
Nanoporous Zirconium Phosphonate Materials with Enhanced Chemical and Thermal Stability for Sorbent Applications
}

\section{Supporting Information}

\author{
Jessica Veliscek-Carolan ${ }^{1 *}$, Aditya Rawal ${ }^{2}$, Daniel T. Oldfield ${ }^{1}$, Gordon J. Thorogood ${ }^{1}$, Nicholas M. \\ Bedford $^{3}$ \\ ${ }^{1}$ ANSTO, Locked Bag 2001, Kirrawee DC, NSW, 2232, Australia \\ ${ }^{2}$ Mark Wainwright Analytical Centre, University of New South Wales, Kensington, NSW, 2052, Australia \\ ${ }^{3}$ School of Chemical Engineering, University of New South Wales, Kensington, NSW, 2052, Australia \\ *Phone: +61 29717 7251, Email: Jessica.Veliscek-Carolan@ansto.gov.au
}

EXAFS $\quad$ S2

Electron Microscopy $\quad$ S3

Nitrogen Porosimetry $\quad$ S6

Fourier Transform Infra-Red (FTIR) Spectroscopy $\quad$ S9

Solid State Nuclear Magnetic Resonance Spectroscopy

Elemental Analysis (leachates) $\quad \mathrm{S} 14$

Sorption $\quad$ S15

SAXS S16

References $\quad S 16$ 

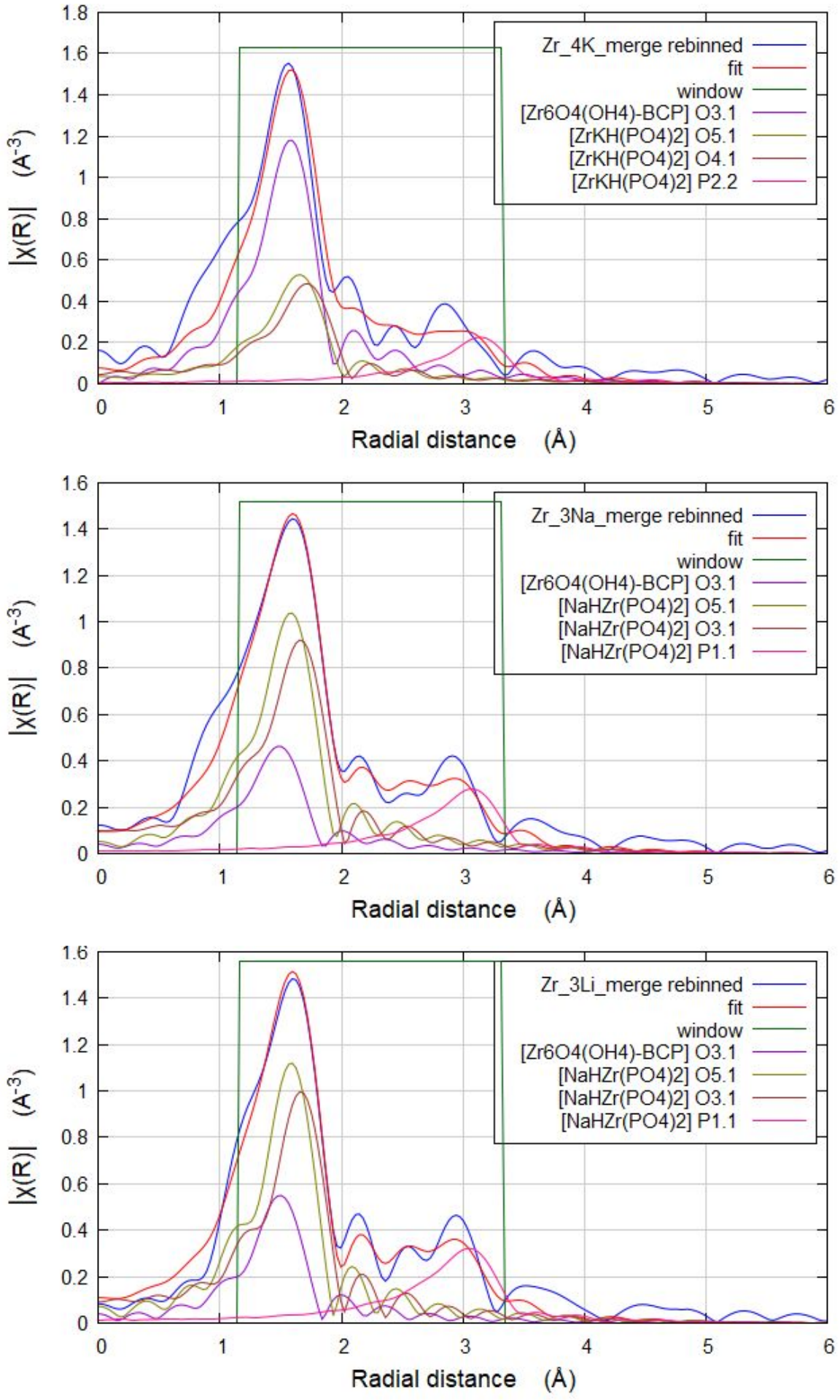

Figure S1: Experimental and calculated Fourier transforms of ZrP_4K (top), ZrP_3Na (middle) and ZrP_3Li (bottom) showing contributions from individual scattering paths of inner-shell $\mathrm{O}$ and $\mathrm{P}$ atoms. 


\section{Electron Microscopy}
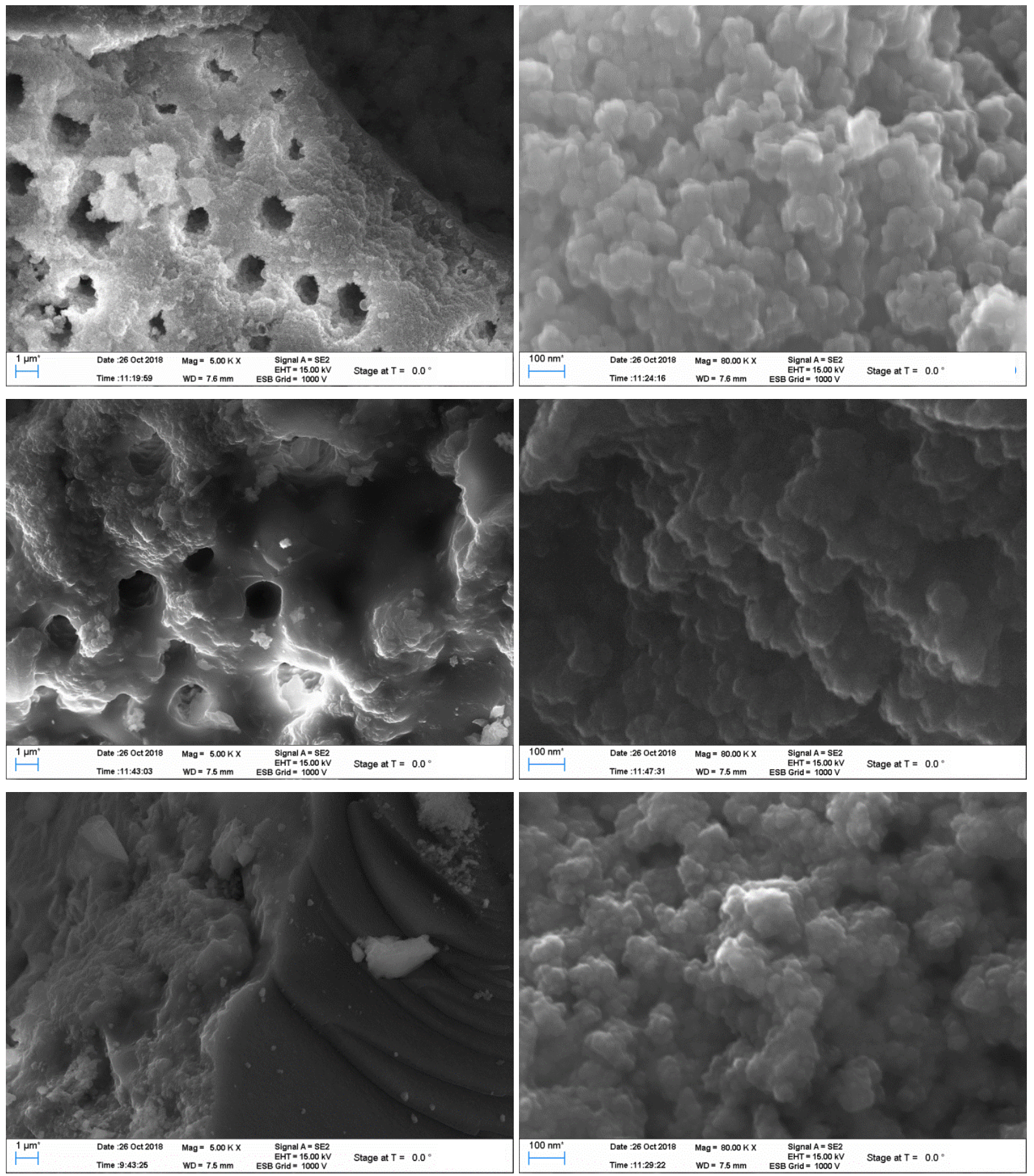

Figure S2: SEM images of ZrP_3K (top), ZrP_4K (middle) and ZrP_5K (bottom), all showing 30-80 nm diameter agglomerates 

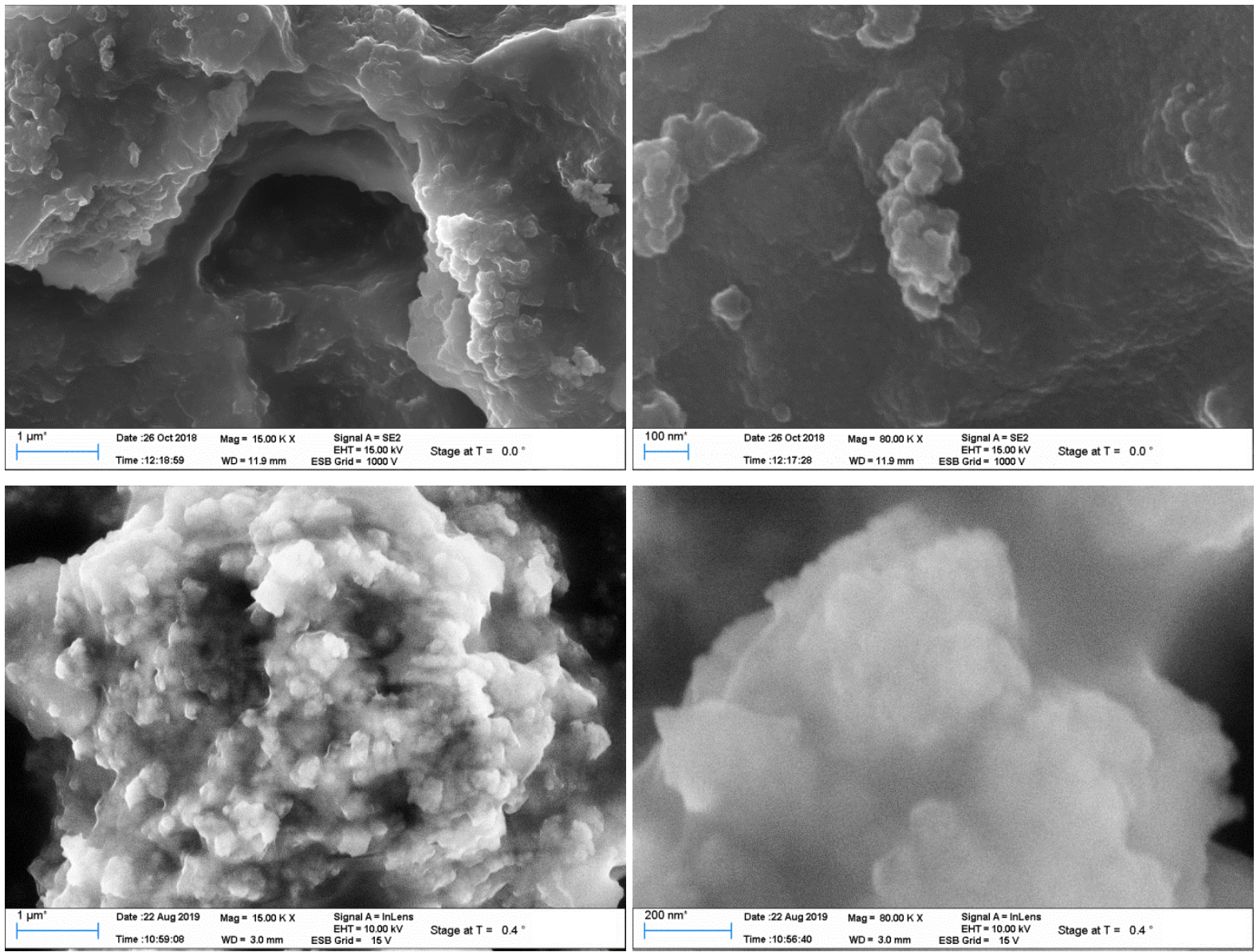

Figure S3: SEM images of ZrP_4Na as-made (top, 40-80 nm) and after leaching (bottom, 100-200 nm diameter agglomerates).

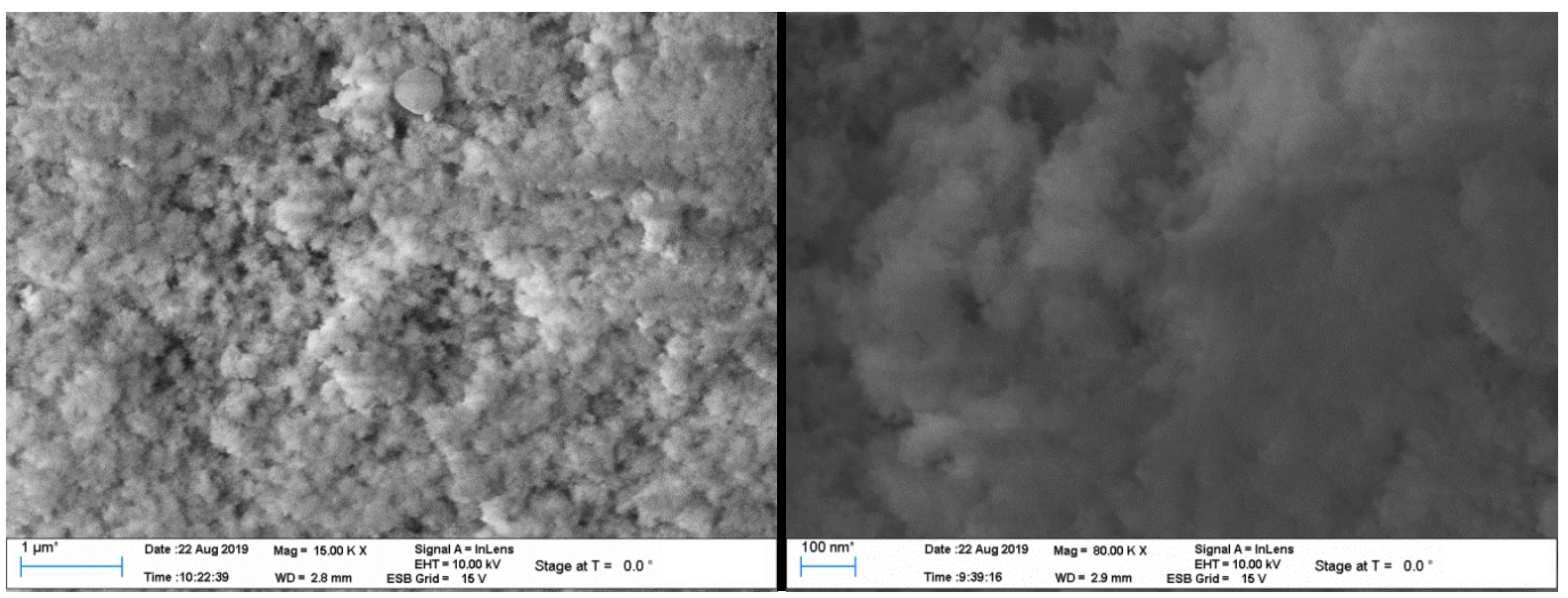

Figure S4: SEM images of ZrP_3Li, showing 20-60 nm diameter agglomerates 

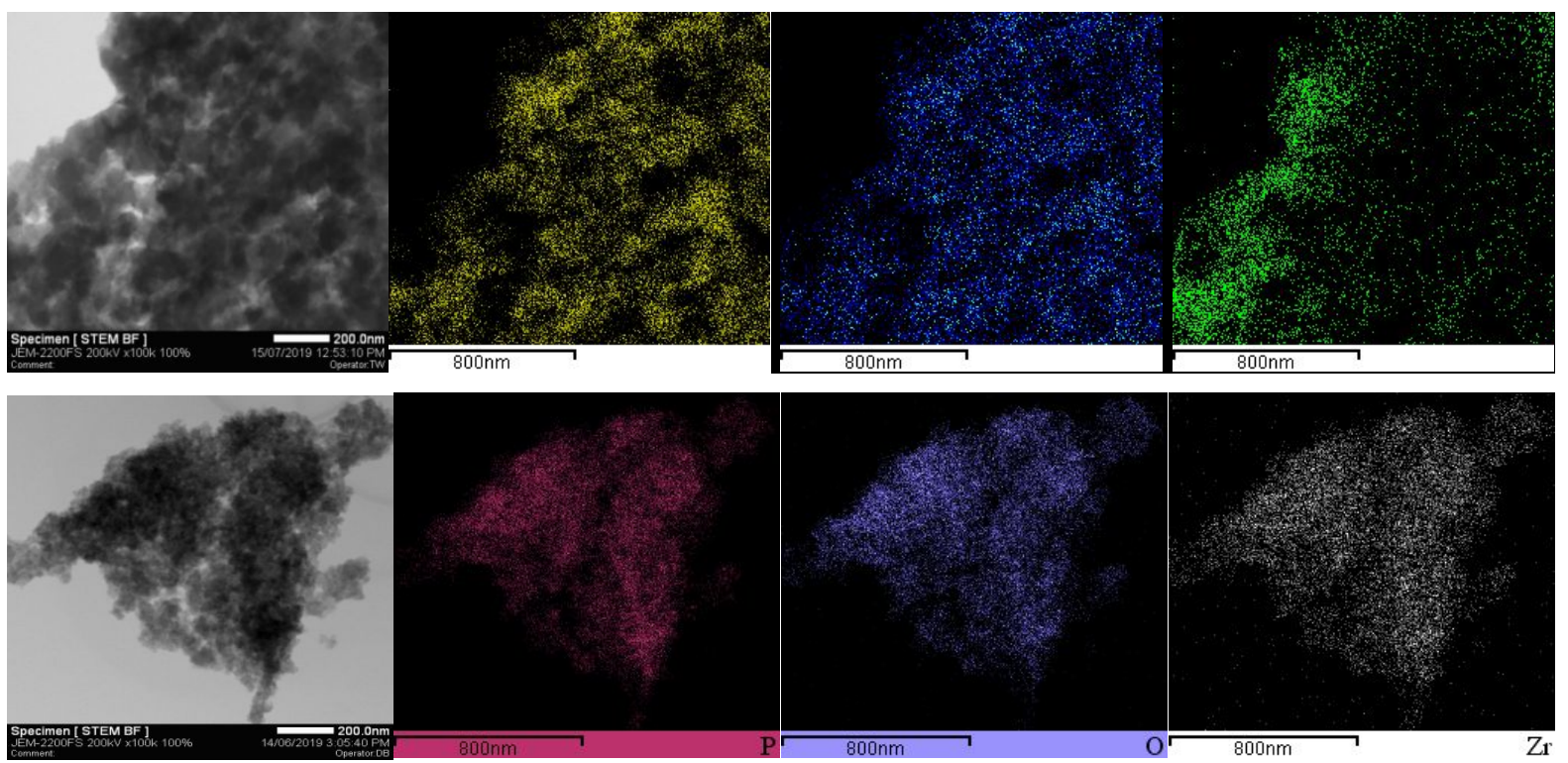

Figure S5: BF STEM and EDS (P, O, Zr) of ZrP_4Na (top) and ZrP_4Li (bottom).

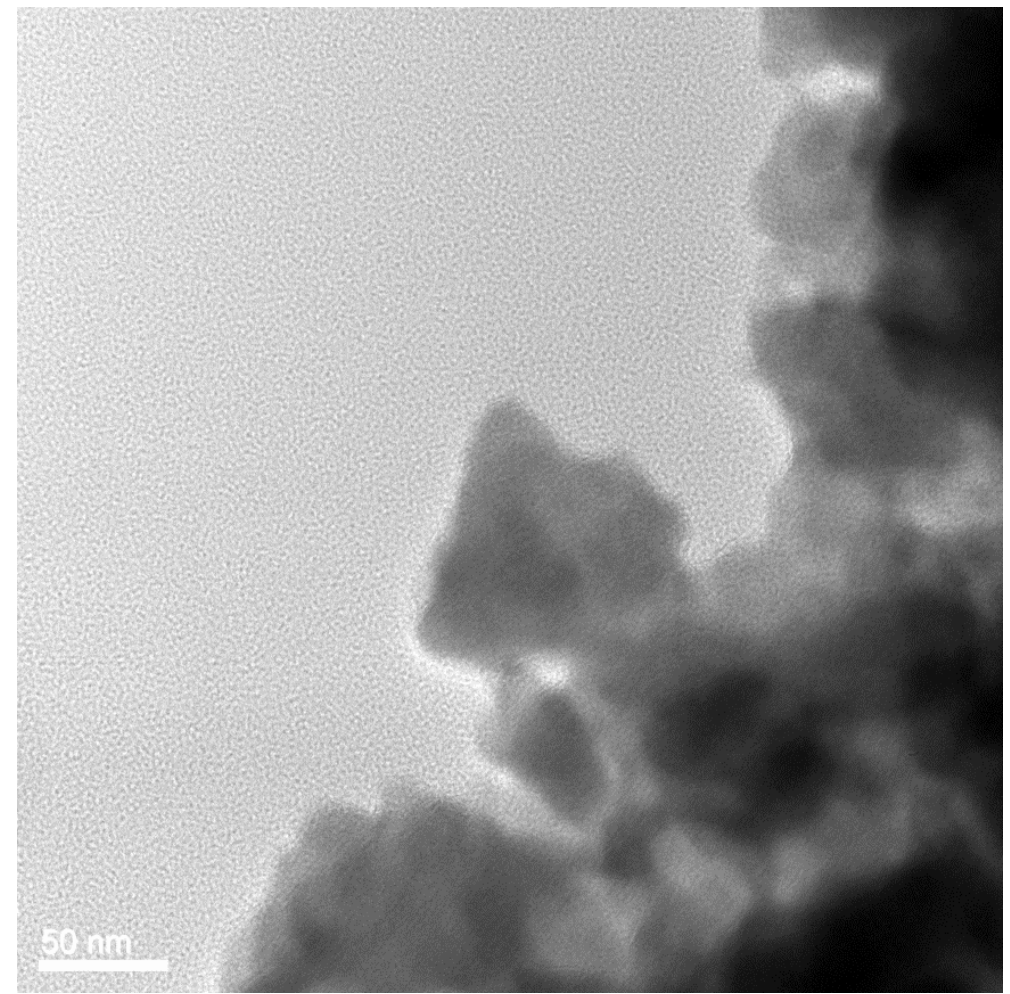

Figure S6: TEM image of ZrP_4Na showing agglomerate size 30-90 nm (consistent with SEM). 


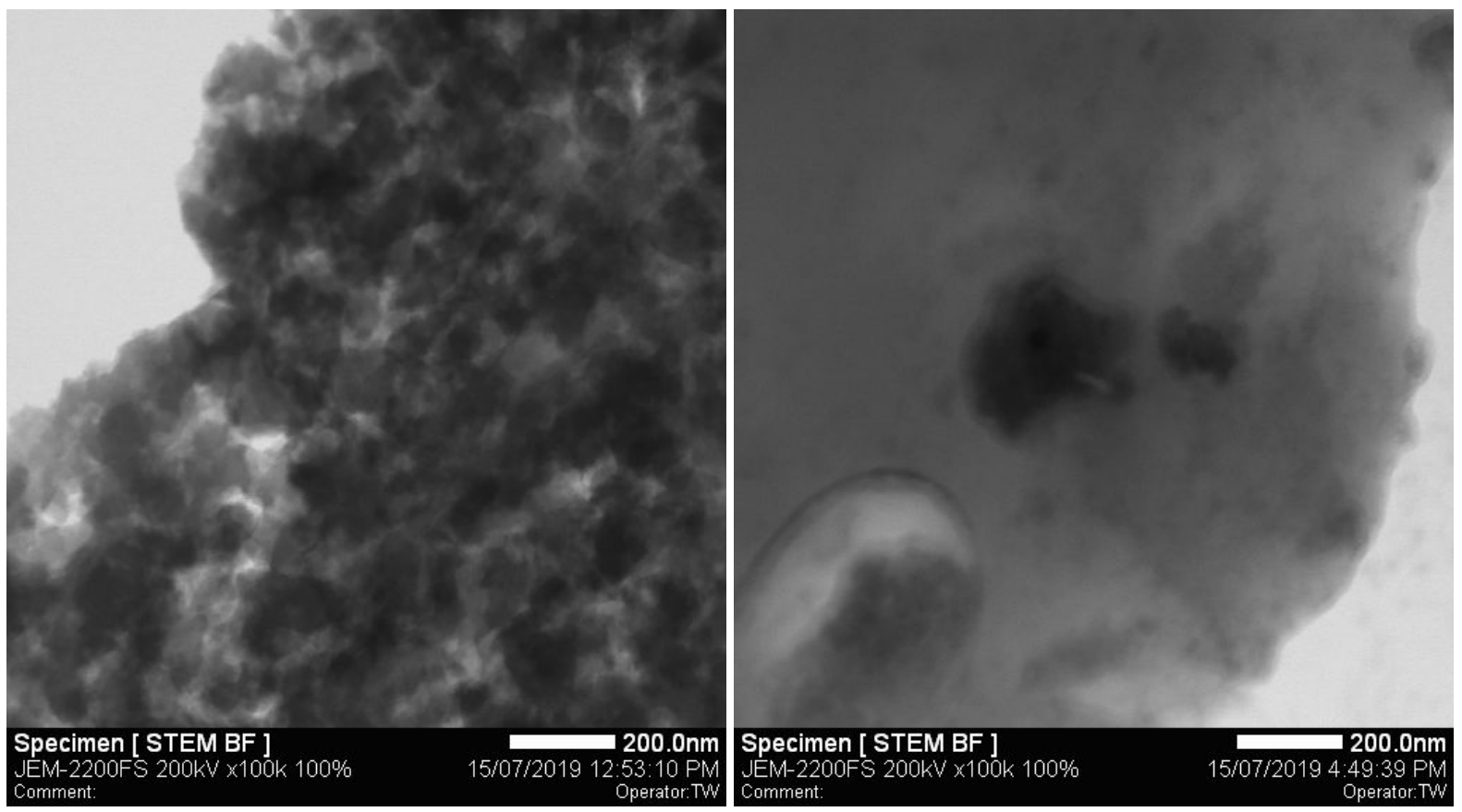

Figure S7: BF STEM images of ZrP_4Na after vacuum drying (left) and after drying at $150{ }^{\circ} \mathrm{C}$ under vacuum (right).

\section{Nitrogen Porosimetry}

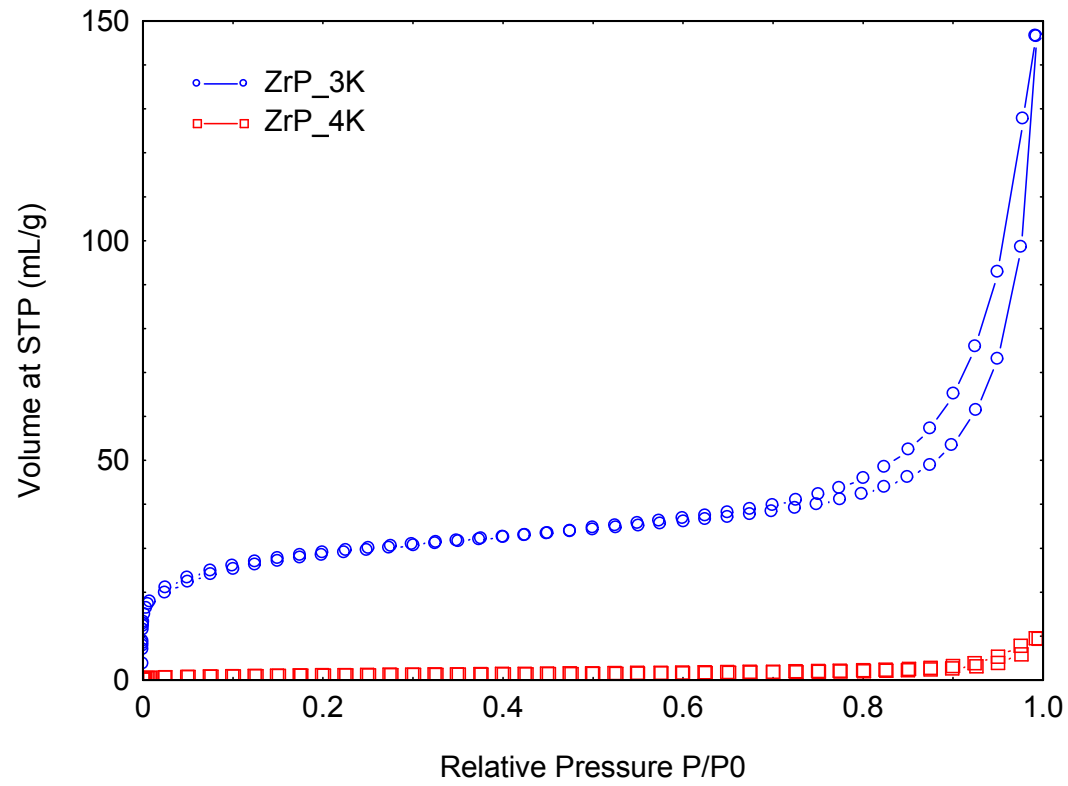

Figure S8: Nitrogen sorption isotherm of ZrP_3K and ZrP_4K (type II/IV) 


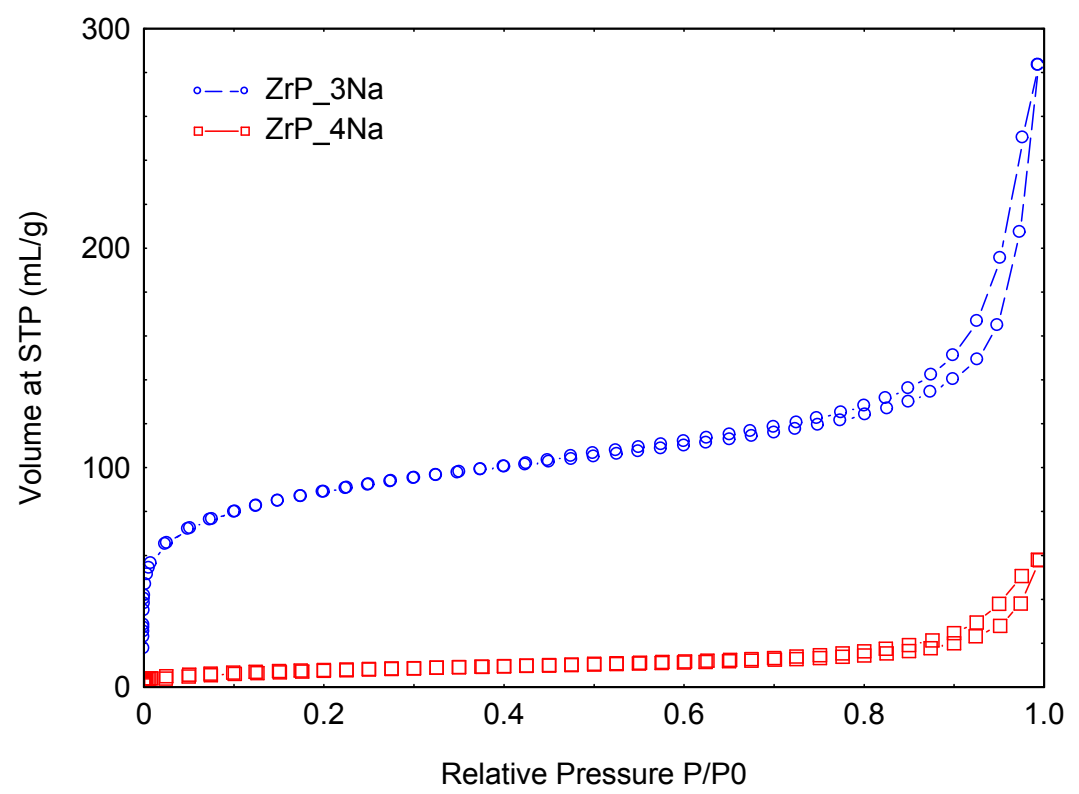

Figure S9: Nitrogen sorption isotherm of ZrP_3Na and ZrP_4Na(type II/IV).

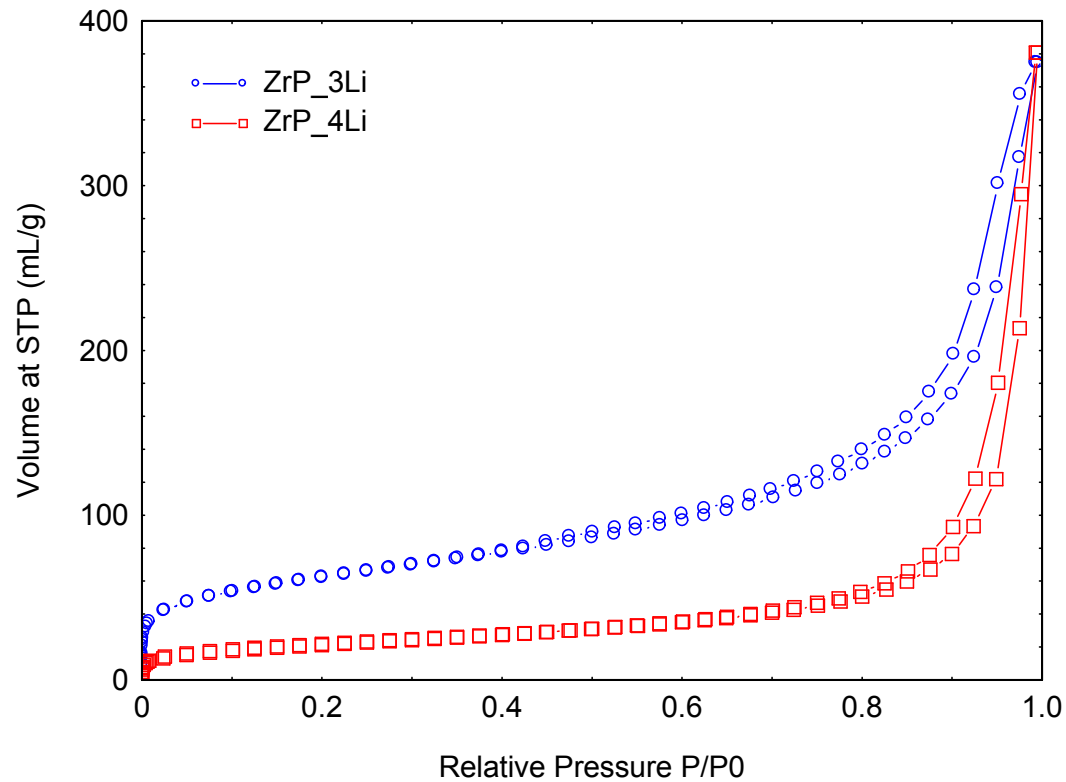

Figure S10: Nitrogen sorption isotherm of ZrP_3Li and ZrP_4Li (type II/IV) 


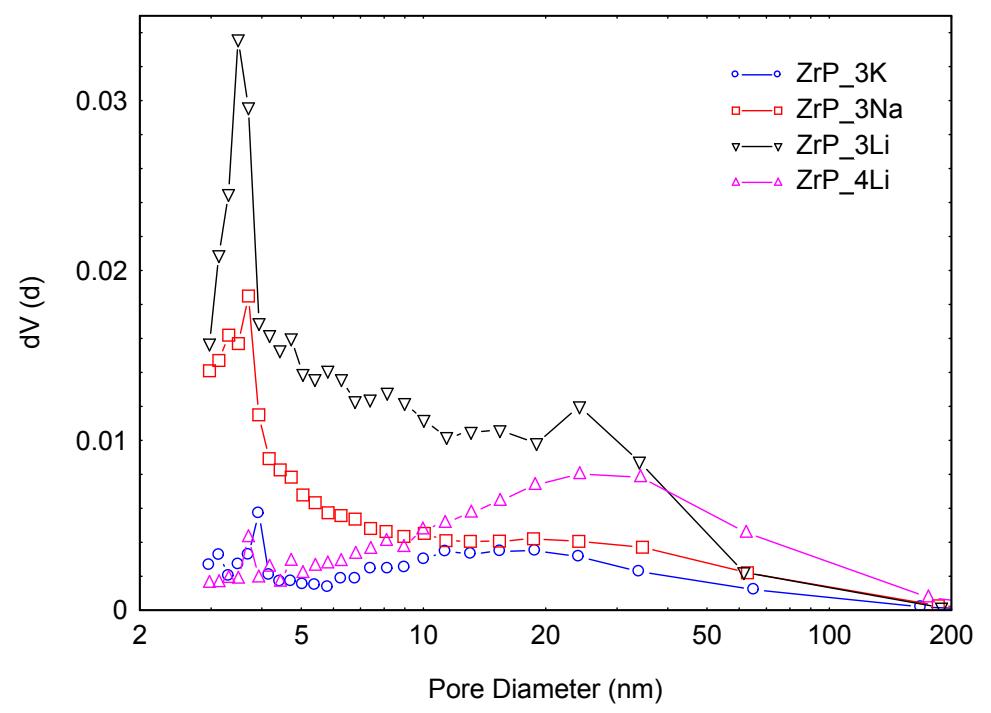

Figure S11: Pore size distribution of Zr-ATMP sorbent materials with pore volume $>0.1 \mathrm{~mL} / \mathrm{g}$. Samples $\mathrm{ZrP} \_4 \mathrm{~K}, \mathrm{ZrP} \_5 \mathrm{~K}$ and $\mathrm{ZrP} \_4 \mathrm{Na}$ did not have sufficient pore volume to provide meaningful pore size data. 


\section{Fourier Transform Infra-Red (FTIR) Spectroscopy}

The FTIR-ATR spectra from 2000 to $650 \mathrm{~cm}^{-1}$ in Figure $\mathrm{S} 6$ show a strong, broad absorbance band from 1250 to $900 \mathrm{~cm}^{-1}$ attributed to P-O stretching vibrations. The main absorbance band centred at 980-970 $\mathrm{cm}^{-1}$ corresponds to $\mathrm{PO}_{3}{ }^{2-}$ (symmetric and asymmetric stretch) and $\mathrm{P}-\mathrm{OH} .{ }^{1}$ The smaller shoulder at $1110 \mathrm{~cm}^{-1}, 1130 \mathrm{~cm}^{-1}$ and $1150 \mathrm{~cm}^{-1}$ for the samples made with $\mathrm{KOH}, \mathrm{NaOH}$ and $\mathrm{LiOH}$ respectively, corresponds to $\mathrm{P}-\mathrm{O}$ groups coordinated to metal centres. ${ }^{2-3}$ The shifting position of this absorbance band suggests it corresponds to $\mathrm{P}-\mathrm{O}-\mathrm{A}+$ groups as well as $\mathrm{P}-\mathrm{O}-\mathrm{Zr}$. There was no consistent change in the FTIR spectra with $\mathrm{pH}$ but the hydroxide cation used caused the P-O absorbance band to shift to higher wavenumbers in the order $\mathrm{K}<\mathrm{Na}<\mathrm{Li}$, especially at $\mathrm{pH} 4$. Since $\mathrm{P}-\mathrm{OH}$ symmetric stretching vibrations appear at the low wavenumber end of the $\mathrm{P}-\mathrm{O}$ stretch region, ${ }^{1,3}$ ZrP_4 Li appears to have the least P-OH groups while ZrP_4K had the most.

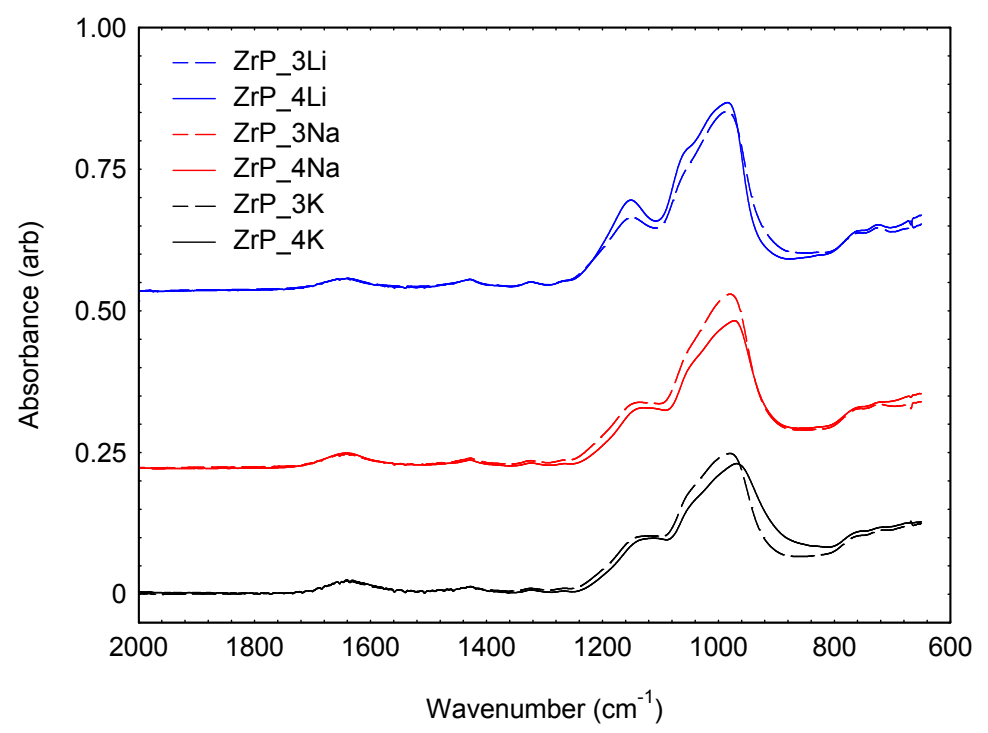

Figure S12: FTIR-ATR of as made Zr-ATMP samples 

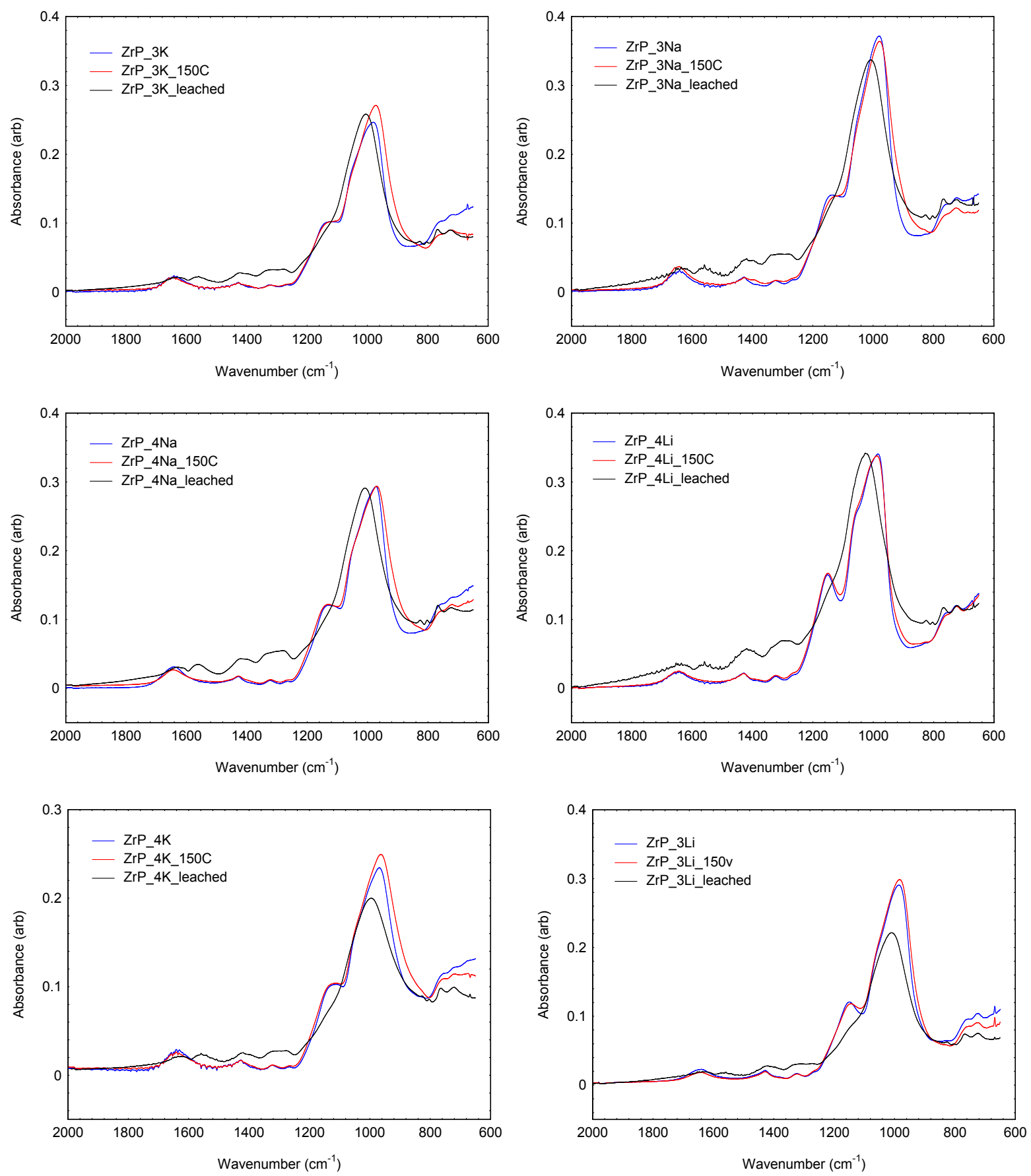

Figure S13: FTIR-ATR of Zr-ATMP samples before and after thermal treatment at $150{ }^{\circ} \mathrm{C}$ or leaching in $5 \mathrm{M} \mathrm{HNO}_{3}$. 


\section{Solid State Nuclear Magnetic Resonance Spectroscopy}

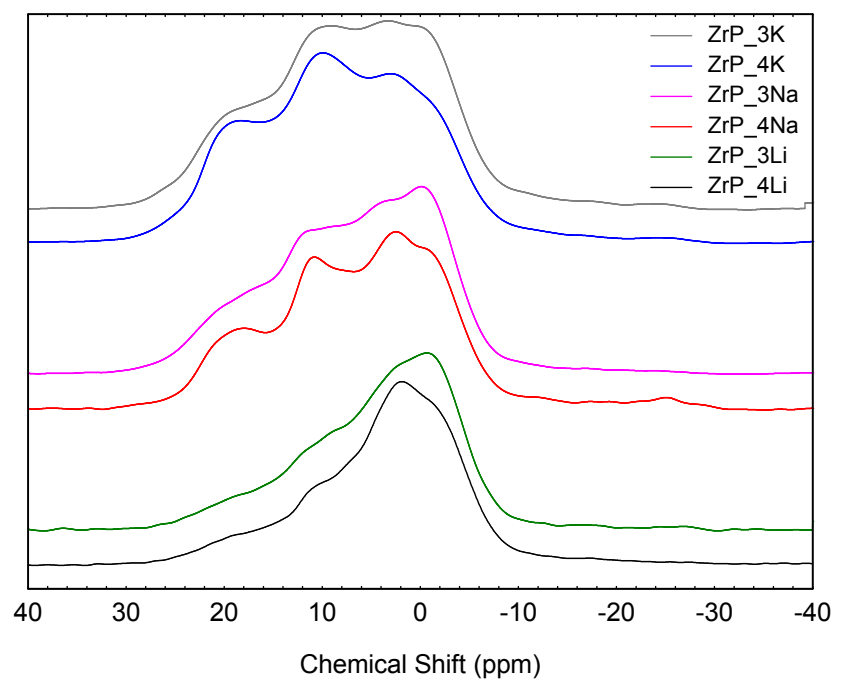

Figure S14: MAS ${ }^{31} \mathrm{P}$ NMR of as-made Zr-ATMP sorbent materials

Table S1: Details of fitting of solid state ${ }^{31} \mathrm{P}$ NMR of Zr-ATMP samples as-made (am), after thermal treatment at $150{ }^{\circ} \mathrm{C}$ under vacuum (150v) and after leaching in $5 \mathrm{M} \mathrm{HNO}_{3}$ (leached).

\begin{tabular}{|c|c|c|c|c|c|c|c|c|c|c|c|c|}
\hline & $\begin{array}{c}\text { Position } \\
\text { (ppm) }\end{array}$ & $\begin{array}{l}\text { FWHM } \\
\text { (ppm) }\end{array}$ & Area (\%) & $\begin{array}{c}\text { Position } \\
\text { (ppm) }\end{array}$ & $\begin{array}{l}\text { FWHM } \\
\text { (ppm) }\end{array}$ & Area (\%) & $\begin{array}{c}\text { Position } \\
\text { (ppm) }\end{array}$ & $\begin{array}{l}\text { FWHM } \\
\text { (ppm) }\end{array}$ & Area (\%) & $\begin{array}{c}\text { Position } \\
\text { (ppm) }\end{array}$ & $\begin{array}{l}\text { FWHM } \\
\text { (ppm) }\end{array}$ & Area (\%) \\
\hline ZrP_3K_am & 18.6 & 7.7 & 0.16 & 10.2 & 8.5 & 0.28 & 2.3 & 11.2 & 0.45 & -2.7 & 5.9 & 0.11 \\
\hline ZrP_4K_am & 19.2 & 7.1 & 0.20 & 10.6 & 8.7 & 0.35 & 1.9 & 10.8 & 0.42 & -2.7 & 4.3 & 0.03 \\
\hline ZrP_3Na_am & 17.9 & 8.1 & 0.14 & 9.9 & 8.1 & 0.28 & 2.9 & 8.2 & 0.31 & -2.6 & 6.5 & 0.27 \\
\hline ZrP_4Na_am & 18.9 & 7.1 & 0.16 & 10.9 & 6.1 & 0.22 & 2.5 & 10.3 & 0.53 & -2.5 & 4.9 & 0.08 \\
\hline ZrP_3Li_am & 19.2 & 7.6 & 0.06 & 10.3 & 9.5 & 0.26 & 2.9 & 8.0 & 0.36 & -2.0 & 6.5 & 0.31 \\
\hline ZrP_4Li_am & 18.6 & 7.7 & 0.07 & 10.0 & 8.1 & 0.20 & 2.4 & 7.7 & 0.48 & -2.7 & 6.6 & 0.25 \\
\hline ZrP_3K_150v & 18.4 & 8.9 & 0.16 & 9.9 & 9.7 & 0.31 & 2.3 & 12.7 & 0.45 & -2.8 & 6.1 & 0.08 \\
\hline ZrP_4K_150v & 18.4 & 8.5 & 0.18 & 10.3 & 9.8 & 0.35 & 2.4 & 13.4 & 0.44 & -2.3 & 5.0 & 0.03 \\
\hline ZrP_3Na_150v & 17.6 & 9.6 & 0.15 & 9.4 & 9.1 & 0.32 & 3.2 & 9.0 & 0.24 & -2.6 & 7.8 & 0.29 \\
\hline ZrP_4Na_150v & 18.7 & 9.6 & 0.15 & 10.8 & 9.6 & 0.32 & 4.3 & 9.1 & 0.31 & -1.9 & 8.6 & 0.21 \\
\hline ZrP_3Li_150v & 18.4 & 10.6 & 0.10 & 10.5 & 8.5 & 0.19 & 3.2 & 9.6 & 0.40 & -2.2 & 7.2 & 0.31 \\
\hline ZrP_4Li_150v & 17.7 & 10.5 & 0.12 & 9.5 & 9.0 & 0.23 & 2.5 & 8.4 & 0.44 & -2.7 & 7.0 & 0.20 \\
\hline ZrP_4K_leached & 19.9 & 8.6 & 0.03 & 13.1 & 5.8 & 0.10 & 4.5 & 9.0 & 0.43 & -3.4 & 8.8 & 0.42 \\
\hline ZrP_3Na_leached & 19.6 & 6.3 & 0.02 & 13.1 & 6.2 & 0.08 & 4.3 & 9.3 & 0.49 & -3.4 & 8.3 & 0.41 \\
\hline ZrP_4Na_leached & & & & 13.3 & 6.2 & 0.09 & 4.4 & 8.7 & 0.42 & -3.3 & 8.3 & 0.46 \\
\hline ZrP_3Li_leached & 20.1 & 8.9 & 0.02 & 12.4 & 7.7 & 0.12 & 4.0 & 9.3 & 0.50 & -3.3 & 8.0 & 0.36 \\
\hline
\end{tabular}




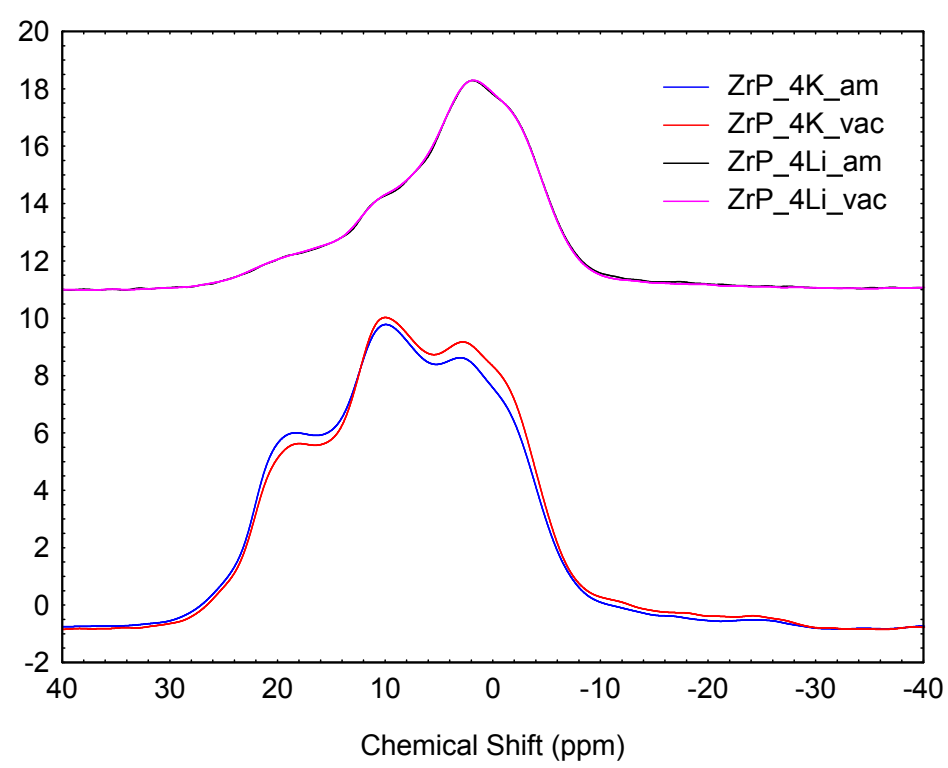

Figure S15: ${ }^{31} \mathrm{P} N M R$ spectra of ZrP_4K and ZrP_4Li as-made and after vacuum drying. ZrP_4K underwent subtle change in chemical structure while ZrP_4Li remained unchanged.
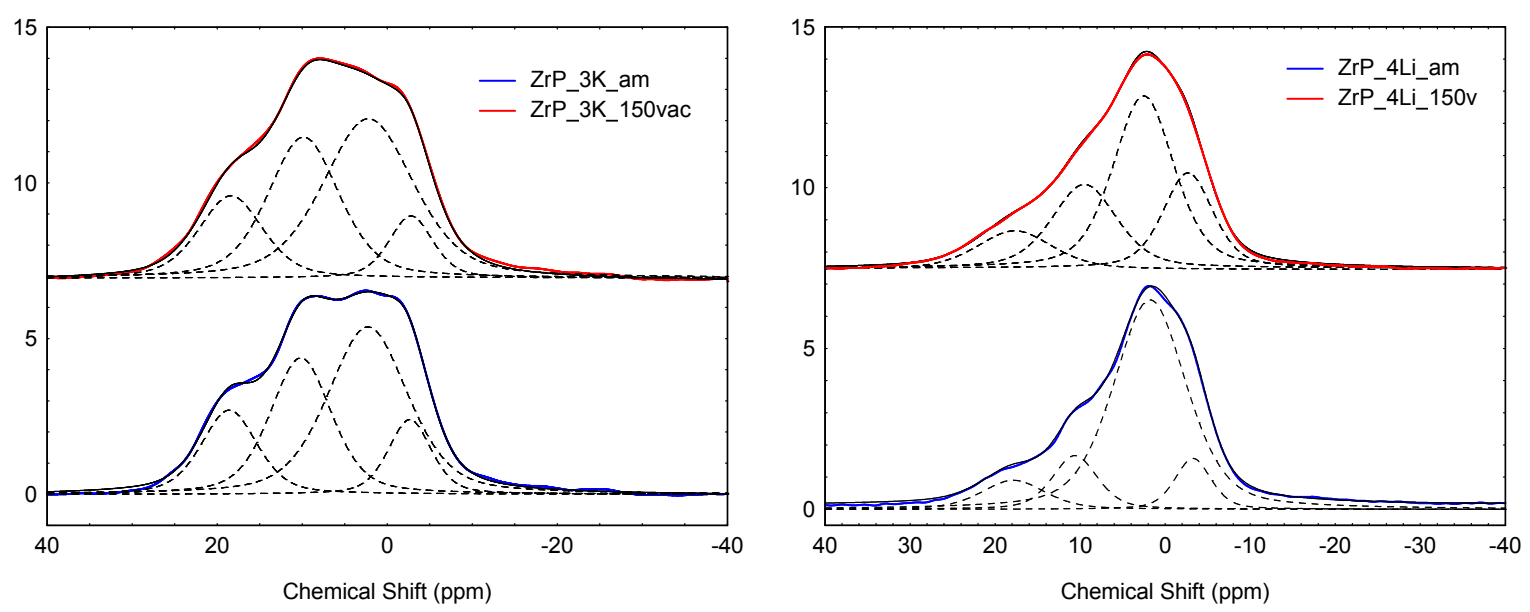

Figure S16: ${ }^{31} \mathrm{P}$ NMR spectra of ZrP_3K and ZrP_4Li before and after thermal treatment at $150{ }^{\circ} \mathrm{C}$ under vacuum. Minimal changes in chemical structure occurred. 


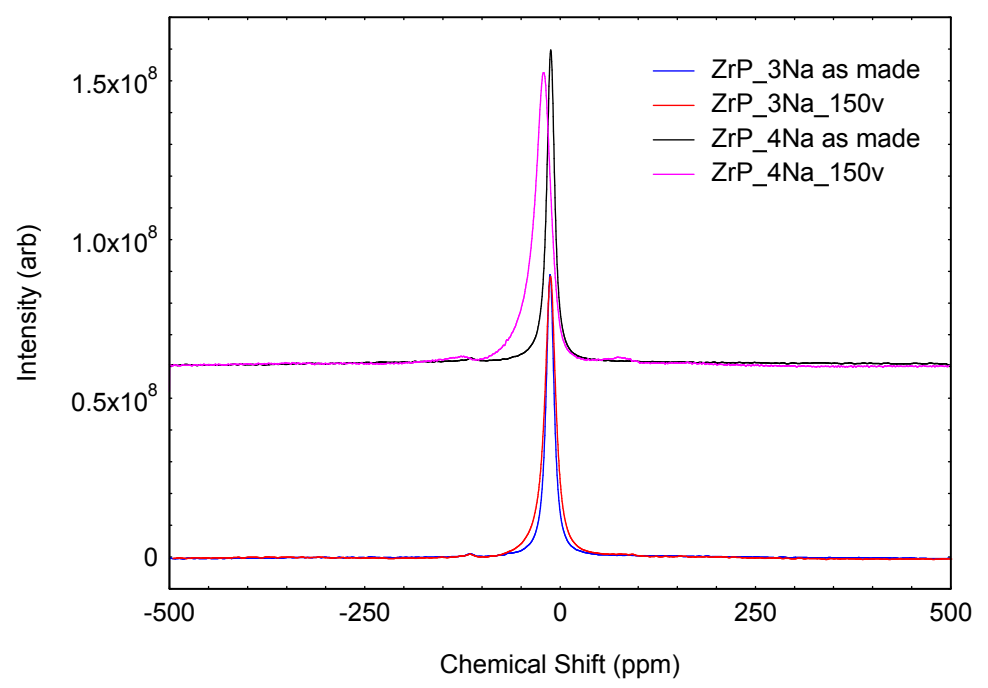

Figure S17: ${ }^{23} \mathrm{Na}$ NMR spectra of ZrP_Na samples before and after thermal treatment. Spectra of the as-made samples are narrower as the $\mathrm{Na}$ is solvated by mobile water.

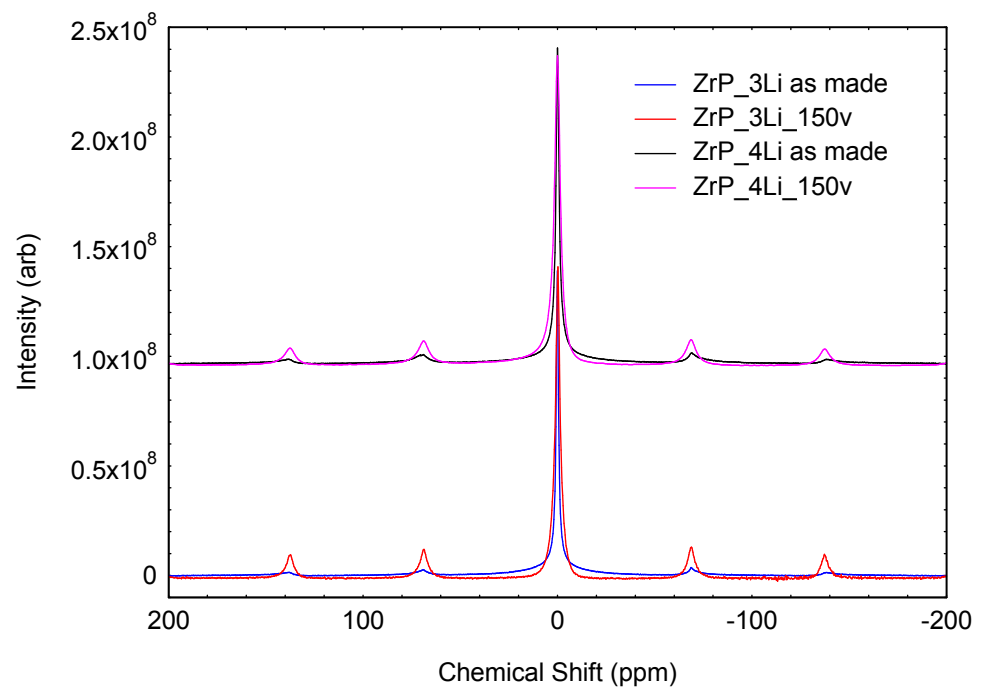

Figure S18: ${ }^{7} \mathrm{Li}$ NMR spectra of ZrP_Li samples before and after thermal treatment. Spectra of the as-made samples are narrower as the Li is solvated by mobile water.

The ${ }^{23} \mathrm{Na}$ and ${ }^{7} \mathrm{Li} \mathrm{NMR}$ spectra of the thermally treated Zr-ATMP samples show an asymmetric line shape indicating disorder and were broadened due to removal of their solvation shells. 

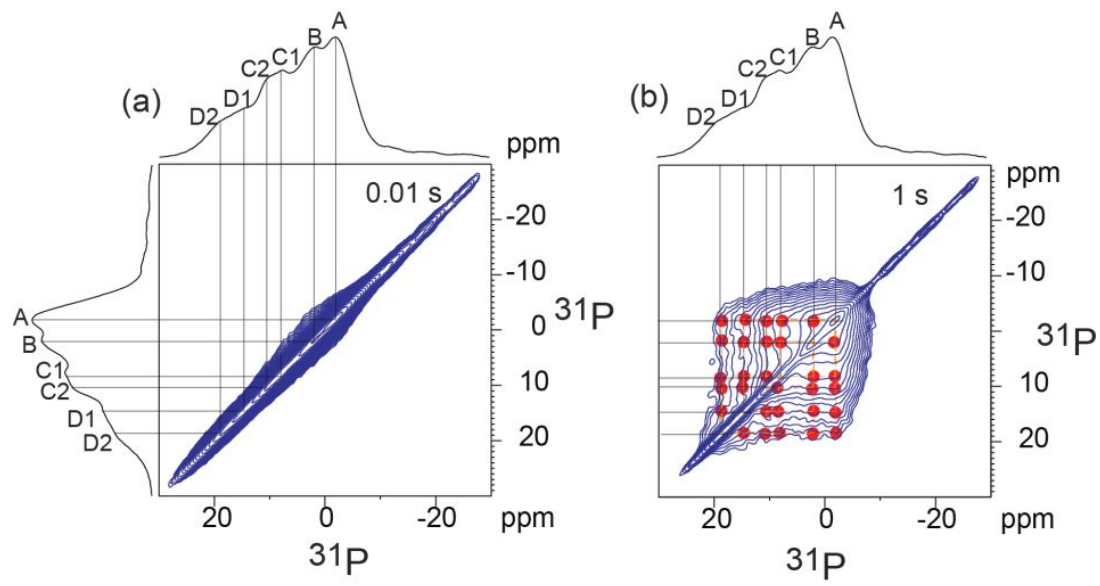

Figure S19: ${ }^{31} \mathrm{P}-31 \mathrm{P} 2 \mathrm{D}$ spin-exchange NMR of ZrP_3Na_am, with spin exchange times of (a) $0.01 \mathrm{~s}$ and (b) $1 \mathrm{~s}$.

\section{Elemental Analysis (leachates)}

Table S2: Percentage loss of $\mathrm{P}$ and $\mathrm{A}+(\mathrm{K}, \mathrm{Na}$ or $\mathrm{Li})$ from $\mathrm{Zr}$-ATMP materials during leaching in $5 \mathrm{M}$ $\mathrm{HNO}_{3}$.

\begin{tabular}{|c|c|c|}
\hline & P loss (\%) & C+ loss (\%) \\
\hline ZrP_3K & $11.3 \pm 0.8$ & $131 \pm 24$ \\
ZrP_4K & $5.3 \pm 0.4$ & $135 \pm 23$ \\
ZrP_3Na & $8.6 \pm 0.9$ & $109 \pm 19$ \\
ZrP_4Na & $11.8 \pm 1.0$ & $112 \pm 16$ \\
ZrP_3Li & $9.4 \pm 0.8$ & $100 \pm 59$ \\
ZrP_4Li & $10.1 \pm 1.1$ & $102 \pm 8$ \\
\hline
\end{tabular}




\section{Sorption}

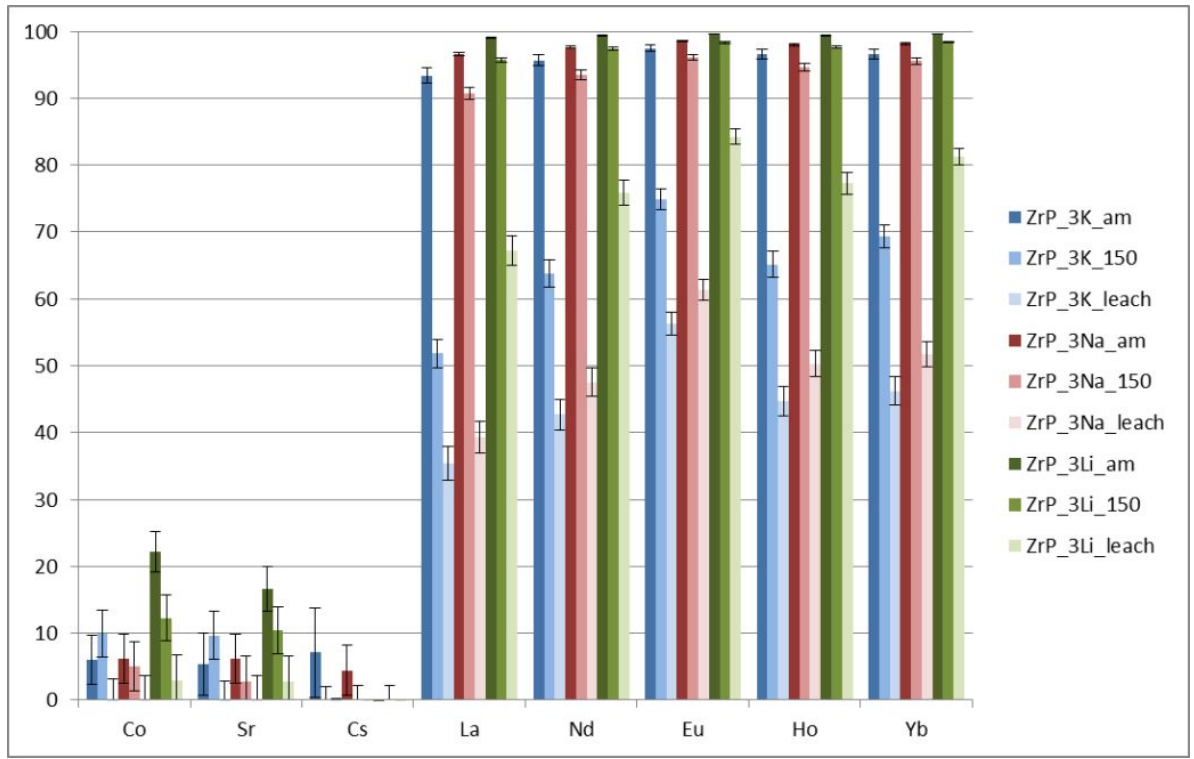

Figure S20: Competitive sorption efficiencies of $0.5 \mathrm{mM} \mathrm{Co}, \mathrm{Sr}$, Cs and $\mathrm{Ln}$ from $0.1 \mathrm{M} \mathrm{HNO}_{3}$ with

Zr-ATMP samples synthesised at $\mathrm{pH} 3$, before and after thermal and chemical treatment

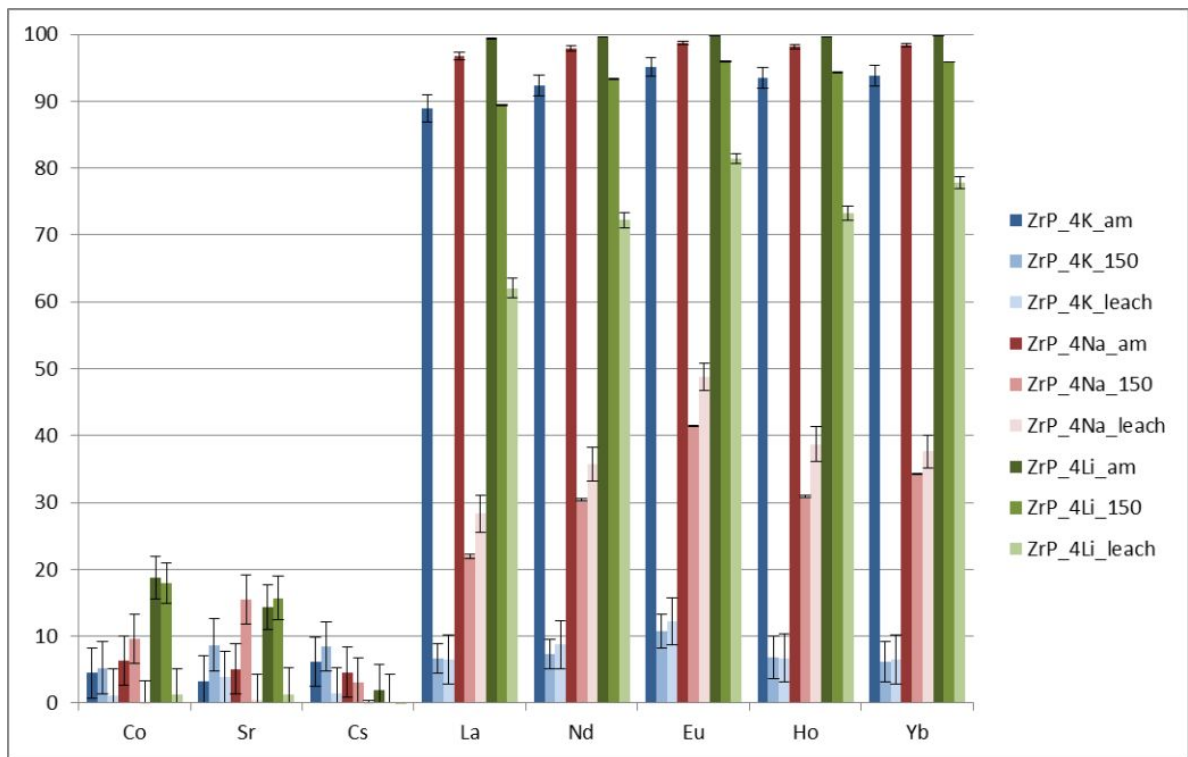

Figure S21: Competitive sorption efficiencies of $0.5 \mathrm{mM} \mathrm{Co}, \mathrm{Sr}$, Cs and $\mathrm{Ln}$ from $0.1 \mathrm{M} \mathrm{HNO}_{3}$ with Zr-ATMP samples synthesised at $\mathrm{pH} 4$, before and after thermal and chemical treatment 


\section{SAXS}

Laboratory small angle x-ray scattering (SAXS) measurements were performed on a Bruker NanoSTAR SAXS camera (Bruker-AXS, Karlsruhe), with 3 pin-hole collimation for point focus geometry. The instrument source was a copper rotating anode ( $0.3 \mathrm{~mm}$ filament) operating at $45 \mathrm{kV}$ and $110 \mathrm{~mA}$, fitted with Montel mirrors, resulting in Cu Ka radiation of wavelength $1.54 \AA$. The SAXS camera was fitted with a Vantec2000 2D detector. The sample to detector distance was chosen to be $730 \mathrm{~mm}$ which provided a Q-range of 0.01 to $0.39 \AA-1$.

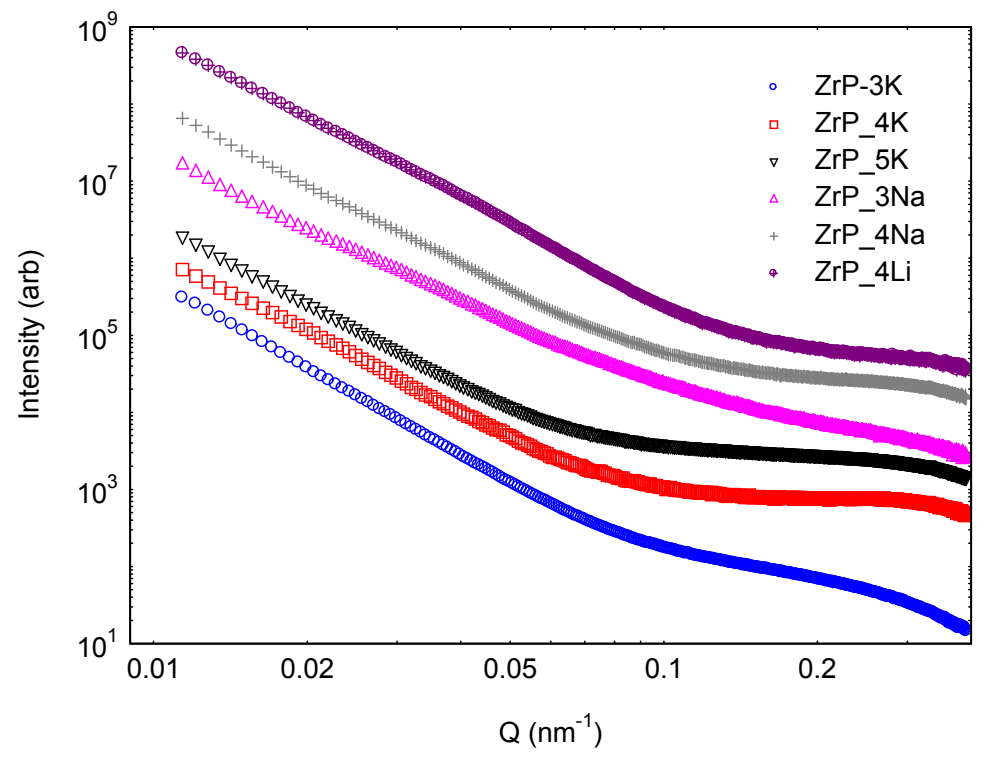

Figure S22: SAXS of as-made Zr-ATMP samples (measured under vacuum), showing showed a $\mathrm{Q}^{-\mathrm{x}}$ dependence with $x$ between 3.5 and 4.0 at low $Q\left(0.01\right.$ to $\left.0.05 \mathrm{~nm}^{-1}\right)$, consistent with scattering from large three-dimensional objects with varying surface roughness. ${ }^{4}$ None of the Zr-ATMP samples show correlation peaks indicative of mesostructures in the measured $Q$ range.

\section{References}

$1 \quad$ R. M. Silverstein, Bassler, G.C., Morrill, T.C., Spectroscopic Identification of Organic Compounds, John Wiley and Sons, Inc., New York, 1963.

2 G. H. Dahl, Block, B.P, Inorganic Chemistry, 1967, 6, 5.

3 M. C. Zenobi, C. V. Luengo, M. J. Avena and E. H. Rueda, Spectrochimica Acta - Part A: Molecular and Biomolecular Spectroscopy, 2010, 75, 1283.

$4 \quad$ J. S. B. Higgins, H.C., Polymers and Neutron Scattering, Oxford University Press, Oxford, 1996. 